\title{
Arterial Blood Gas: Bowling Wide and Poor Wicketkeeping
}

\author{
Rajesh K Pande $\odot$
}

\begin{abstract}
Arterial blood gas $(A B G)$ is an essential point-of-care test to identify the $\mathrm{pH}$, metabolic, and respiratory status of critically ill patients. In addition, it provides useful information about co-oximetry, lactate, electrolytes, and other parameters. Studies show that it is widely prescribed but the impact of $A B G$ result on clinical care is limited. Protocols addressing effective utilization of ABG can address and help in minimizing cost and complications.
\end{abstract}

Keywords: Arterial blood gas, ICU, Point-of-care testing, Protocol, Utilization.

Indian Journal of Critical Care Medicine (2021): 10.5005/jp-journals-10071-23735

Even though the indications are not well defined, arterial blood gas (ABG) analysis continues to remain one of the most commonly done tests in critically ill patients. ${ }^{1}$ Some of the potential advantages of $A B G$ include help in diagnosis, ventilator management, and guiding treatment plans including acid-base and electrolyte management. ${ }^{2}$ In fact, ABG has become an essential point-of-care test (POCT) to look at the $\mathrm{pH}$, metabolic, and respiratory status of these patients. In addition, co-oximetry, lactate, electrolytes, and other parameters add more punch to this critical information.

Initial attempts to use blood $\mathrm{pH}$ to improve diagnosis and management were made by Poul Astrup and Bjørn Ibsen during the European polio epidemic. ${ }^{3}$ The popular bicarbonate-based analysis (Boston school), which characterizes acids as hydrogenion donors and bases as hydrogen-ion acceptors, uses the carbonic acid-bicarbonate buffer system. ${ }^{4,5}$ In this approach, primary respiratory $\left(\mathrm{PCO}_{2}\right)$ or metabolic $\left(\mathrm{HCO}_{3}\right)$ changes result in a secondary adjustment in metabolic or respiratory parameters. It identifies six disorders-two metabolic (acidosis, alkalosis) and four respiratory (acute and chronic respiratory acidosis and alkalosis) based on six bicarbonate-based formulas, based on the assumption that base excess is not independent of $\mathrm{PCO}_{2}$ in vivo. These formulas are also part of standard blood gas teaching in India. The other Copenhagen school relies on standard base excess (SBE), which is independent of PCO2 to interpret the data. ${ }^{5}$ Another reintroduced old concept gaining traction is the concept of using strong ion deficit (SID), rather than $\mathrm{pH}$ (Stewart approach) to define acid-base disorders. ${ }^{6}$

Most common reasons for doing ABG include weaning from the ventilator, with $\mathrm{FIO}_{2}$ and pressure support adjustments cited as most common reasons, but studies looking at the correlation between $A B G$ orders and weaning decisions have shown that $A B G$ values did not really affect clinical decision-making in as high as $93 \%$ of cases. ${ }^{7}$ A limited number of published studies look at the utilization of $A B G$ in clinical decision-making, and most of them are inconclusive being single center involving a small number of subjects. One such study looking at the usefulness of ABG in patients presenting with acute dyspnea to the emergency department found it to be of limited value, but interestingly, $\mathrm{pH}$ was found to be an independent predictor of 12-month mortality, prompting consideration for the substitution of arterial by venous blood in these patients. ${ }^{8}$
Centre for Critical Care, BLK Super Speciality Hospital, New Delhi, India

Corresponding Author: Rajesh K Pande, Centre for Critical Care, BLK Super Speciality Hospital, New Delhi, India, Phone: +91 9810536268, e-mail: rajeshmaitree2000@yahoo.com

How to cite this article: Pande RK. Arterial Blood Gas: Bowling Wide and Poor Wicketkeeping. Indian J Crit Care Med 2021;25(2):119-120.

Source of support: Nil

Conflict of interest: None

Most $A B G$ utilization surveys have reported a non-utilization of $A B G$ values in clinical decision-making. This single-center prospective observational study looks at two important aspects, reason for ordering the test and application of test result in clinical decision-making. ${ }^{9}$ About $70 \%$ of the tests were done during regular hours with a large percentage $(80 \%)$ done without any clear indications. Clinical interventions based on ABG report were made in $26.29 \%$ of patients only, and surprisingly among those where metabolic assessment was listed as a reason for doing ABG, the study did not find any reason to assess metabolic status in as high as $93.5 \%$ of patients. It just means that critical care physicians and nurses are still ordering ABG routinely more like a habit and not always utilizing the results in clinical practice. Ventilator and $\mathrm{FIO}_{2}$ adjustments were done only in 13.6 and $0.81 \%$ of patients, respectively, which again prompt us to rethink our approach toward casually ordering ABG in ICU. Although a number of attempts at arterial puncture, pain, local hematoma, arterial vasospasm, air or thrombus embolism, hemorrhage, and other complications were not measured, these could have been significant concerns as only about $50 \%$ of patients had an indwelling arterial cannula. Even though reported complications are less with arterial cannulation, repeated arterial punctures can increase these complications.

Unnecessarily drawn samples possibly reflect fear of litigation, easy access to arterial lines, routine work patterns in ICUs, and habit. ${ }^{10,11}$ As high as $30 \%$ of the ABG tests may be unnecessary. ${ }^{12}$ Most protocol-based studies have shown a significant 24 to $44 \%$ reduction in frequency of $A B G$ sampling after protocol implementation with not much change in safety indicators. ${ }^{13}$ However, a computer-based intervention study prompting mandatory display of previous $A B G$ values and oxygen saturations while ordering new tests did not

C) Jaypee Brothers Medical Publishers. 2021 Open Access This article is distributed under the terms of the Creative Commons Attribution 4.0 International License (https://creativecommons.org/licenses/by-nc/4.0/), which permits unrestricted use, distribution, and non-commercial reproduction in any medium, provided you give appropriate credit to the original author(s) and the source, provide a link to the Creative Commons license, and indicate if changes were made. The Creative Commons Public Domain Dedication waiver (http://creativecommons.org/publicdomain/zero/1.0/) applies to the data made available in this article, unless otherwise stated. 
show significant changes in ABG utilization, possibly because a large number of tests were ordered by non-physician users. ${ }^{13}$

Adhering to protocols has been reported to reduce annual costs, which ranged from 10,000 USD in Nepal to 100,000 US dollars in the United States. ${ }^{12,14}$ There have also been concerns about blood loss, patient discomfort, and complications related to uncontrolled ABG sampling, which can be reduced if some kinds of protocols or algorithms are followed..$^{15}$ In the present study, pain, hematoma, and other complications (not reported) could have been major concerns as only about $50 \%$ of patients had an indwelling arterial cannula. Many protocols do not identify indications for ABG sampling, which should be essential component of such protocols to control unnecessary sampling.

Finally, this study brings focus back on effective utilization and better clinical application of ABG, which will help us reduce unnecessary costs and complications associated with arterial puncture. However, these results cannot be generalized as the study suffers from the same drawback as previous studies-single center, smaller number, and limited duration of the study. A larger multicenter longitudinal prospective study looking at the effectiveness of $A B G$ is needed.

\section{OrCID}

Rajesh K Pande 이 https://orcid.org/0000-0002-0149-727X

\section{References}

1. Lundberg GD. The need for an outcome research agenda for clinical laboratory testing. JAMA 1998;280(6):565-566. DOI: 10.1001/ jama.280.6.565.

2. Sood P, Paul G, Puri S. Interpretation of arterial blood gas. Indian J Crit Care Med 2010;14(2):57-64. DOI: 10.4103/0972-5229.68215.

3. West JB. The physiological challenges of the 1952 Copenhagen poliomyelitis epidemic and a renaissance in clinical respiratory physiology. J Appl Physiol 2005;99(2):424-432. DOI: 10.1152/ japplphysiol.00184.2005.
4. Siggaard-Andersen O, Fogh-Andersen N. Base excess or buffer base (strong ion difference) as measure of a nonrespiratory acid-base disturbance. Acta Anaesthesiol Scand Suppl 1995;107:123-128. DOI: 10.1111/j.1399-6576.1995.tb04346.x.

5. Severinghaus JW. Siggaard-Andersen and the "Great Trans-Atlantic Acid-Base Debate". Scand J Clin Lab Invest Suppl 1993;214:99-104. PMID: 8332859. DOI: 10.1080/00365519309090685.

6. Morgan TJ. The Stewart approach-one clinician's perspective. Clin Biochem Rev 2009;30(2):41-54. PMID:19565024.

7. Salam A, Smina M, Gada P, Tilluckdharry L, Upadya A et al. The effect of arterial blood gas values on extubation decisions. Respir Care 2003:48(11):1033-7. PMID: 14585115.

8. Burri E, Potocki M, Drexler B, Schuetz P, Mebazaa A. Value of arterial blood gas analysis in patients with acute dyspnea: an observational study. Crit Care 2011;15(3):R145. DOI: 10.1186/cc10268.

9. Chandran J, D'Silva C, Sriram S, Krishna B. Clinical Utility of Arterial Blood Gas Test in an Intensive Care Unit: An Observational Study. Indian J Crit Care Med 2021;25(2):172-175.

10. Muakkassa FF, Rutledge R, Fakhry SM, Meyer AA, Sheldon GF. ABGs and arterial lines: the relationship to unnecessarily drawn arterial blood gas samples. J Trauma 1990;30(9):1087-1093 [discussion 1093-5]. PMID: 2120467.

11. Roberts D, Ostryzniuk P, Loewen E, Shanks A, Wasyluk T, et al. Control of blood gas measurements in intensive-care units. The Lancet 1991;337(8757):1580-1582. DOI: 10.1016/0140-6736(91)93271-a.

12. Melanson SEF, Szymanski T, Rogers Jr SO, Jarolim P, Frendl G, et al. Utilization of arterial blood gas measurement in a large tertiary care hospital. Am J Clin Pathol 2007;127(4):604-609. DOI: 10.1309/ ELH5BPQ0T17RRK0M.

13. Bansal P, Aronsky D, Talbert D, Miller RA. A computer based intervention on the appropriate use of arterial blood gas. Proc AMIA Symp 2001:32-36. PMID: 11825152.

14. Khanal S. Utilization of arterial blood gas measurement in a tertiary care hospital. J Anaesth Crit Care Open Access 2016;6(2):00219. DOI: 10.15406/jaccoa.2016.06.00219.

15. DellaVolpe JD, Chakraborti C, Cerreta K, Romero CJ, Firestein $\mathrm{CE}_{\mathrm{s}}$ et al. Effects of implementing a protocol for arterial blood gas use on ordering practices and diagnostic yield. Healthc (Amst). 2014;2(2):130-135. DOI: 10.1016/j.hjdsi.2013.09.006. 